\title{
A Long-term Period Performance Assessment of a Building Integrated Photovoltaic System
}

\author{
Mustafa Araz ${ }^{1, *}$ Emrah Biyikt ${ }^{1}$, and Arif Hepbasli ${ }^{1}$, \\ ${ }^{1}$ Department of Energy Systems Engineering, Faculty of Engineering, Yasar University, 35100 Bornova, İzmir, Turkey
}

\begin{abstract}
Building Integrated Photovoltaic (BIPV) systems can be defined as PV modules, which can be integrated in building's envelope by replacing conventional building materials such as windows, tiles etc. and have an impact on the functionality of the buildings. Considering the huge share (40\%) of buildings in total energy consumption and nearly zero-energy building target of the European Union (EU), BIPV systems present a sustainable solution and have gained increased interest in last years. In this study, the performance of a BIPV system, which was installed on Feb. 8, 2016 on the façade of a campus building at Yasar University, İzmir, Turkey within the framework a EU/FP7 project and has a capacity of $7.44 \mathrm{~kW}_{\mathrm{p}}$, is evaluated for a three-year period using first and second laws of thermodynamics. Within this context, real (experimental) monthly and yearly electricity productions are determined and compared with the results obtained from the simulations. Energy and exergy efficiencies and performance ratios of the system are also calculated based on the cell and total areas.
\end{abstract}

\section{Introduction}

Energy conservation in a building is an important issue from the point of view of global warming and depletion of fossil fuels. Nowadays, there is a strong need to design buildings, in which renewable sources of energy are utilized, in order to use minimum fossil fuel based conventional power [1]. At present, the share of buildings in total energy consumption is about $40 \%$ in the EU and there are some legislations such as the Building Energy Directive that targets nearly zero-energy buildings [2]. Considering these, solar energy seems to be a competitive option for buildings. On the other due to the limited roof area of buildings, integrating photovoltaic (PV) systems into the building façades and roofs represents a significant solution. In fact, the average compounded growth rate of the BIPV technology between 2014 and 2020 is estimated to be 39 and the anticipated annual global BIPV installation in 2020 is $11 \mathrm{GW}$, which was only $1.5 \mathrm{GW}$ in 2014 [3]. BIPVs have also gained the attention of academicians from all over the world and therefore there are numerous studies in the literature related to them. Biyik et al. [4], conducted a comprehensive review where they examined studies related BIPVs and BIPV/Ts. Readers can refer to this review study for more information.

In this study, the performance of a BIPV system, which was installed on Feb. 8, 2016 on the façade of a campus building at Yasar University, İzmir, Turkey within the framework a EU/FP7 project and has a capacity of 7.44 $\mathrm{kW}_{\mathrm{p}}$, is evaluated for a three-year period using first and second laws of thermodynamics. Within this context, real (experimental) monthly and yearly electricity productions are determined and compared with the results obtained from the simulations.

\section{System description}

The BIPV system was installed to a south-east facing façade of a building at Yasar University and it consists of 48 mono-crystalin PV panels, each with a capacity of 155 $\mathrm{Wp}$, making a total capacity of $7.44 \mathrm{kWp}$. These panels are installed in four rows as can be seen from Fig. 1 and there is a $150 \mathrm{~mm}$ gap between the wall and panels. 24 panels above and below the windows are connected in series and these two strings are connected parallelly to the $7 \mathrm{~kW}$ inverter, which has two independent MPPT inputs. The total area of the system is $57.6 \mathrm{~m}^{2}$, while the cell area is only $42.08 \mathrm{~m}^{2}$ due to the $30 \%$ transparency rate.

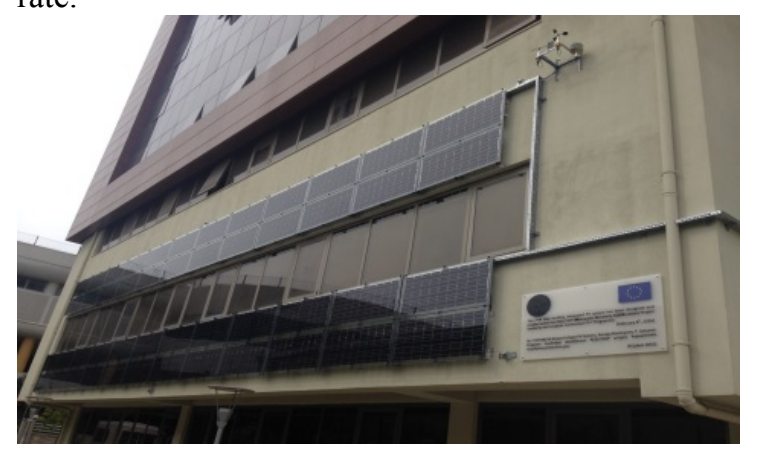

Fig. 1. A picture of the system [5].

Various measurement instruments have been installed on the system and are illustrated in Fig. 2. 


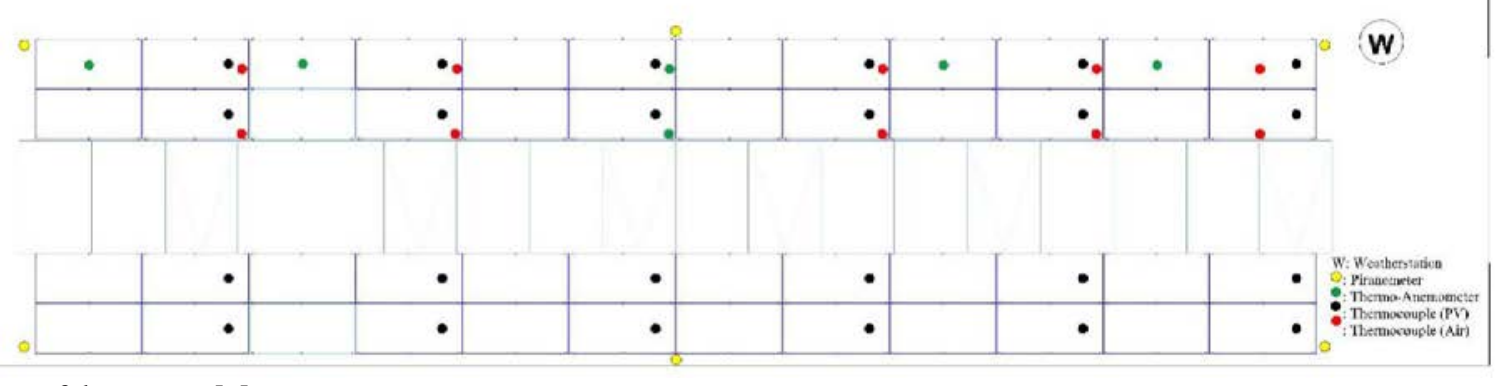

Fig. 2. P\&ID of the system [5].

As it can be seen from this figure, the surface temperatures of the PV modules are measured on 24 points, while the air temperatures between the wall and the modules are measured at 12 different location. The air velocity behind the modules is also measured on two points. For the irradiation measurements, 6 piranometers are mounted on the system (4 in the corners and 2 at midpoints) while weather-station is located just next to the upper string. Wind velocity and direction, air temperature and humidity are measured at this point. All these measurements are continuously recorded on a 60channel internet-connected data logger. The inverter on the other hand serves also as a measuring instrument and all electrical data are recorded to a cloud service by 15 minute intervals.

\section{Analysis}

Energy efficiency $(\eta)$ and exergy efficiency $(\varphi)$ of the system can be calculated by dividing the total power generation for a period of time (day, month, year) to the total irradiation received by the BIPV system at the same period [6].

$$
\begin{gathered}
\eta=\frac{\sum \dot{W}}{\sum A G} \\
\psi=\frac{\sum \dot{W}}{\sum \dot{E} x_{\text {sol }}}
\end{gathered}
$$

Here the exergy of solar irradiation can be found by using Petela's equation [7]:

$$
\dot{E} x_{\text {sol }}=A G\left[1-\frac{4}{3}\left(\frac{T_{0}}{T_{\text {sun }}}\right)+\frac{1}{3}\left(\frac{T_{0}}{T_{\text {sun }}}\right)^{4}\right]
$$

Another performance indicator for PV systems is the performance ratio (PR) and it can be obtained from Eq. 4. This can be calculated monthly or annualy for different time steps $(\tau)$.

\section{Results and Discussion}

In the first part of the study, monthly electricity generations for 2016, 2017 and 2018 are estimated and compared to the results obtained from TRNSYS [8] simulation. This comparison is illustrated in Fig. 3, below.

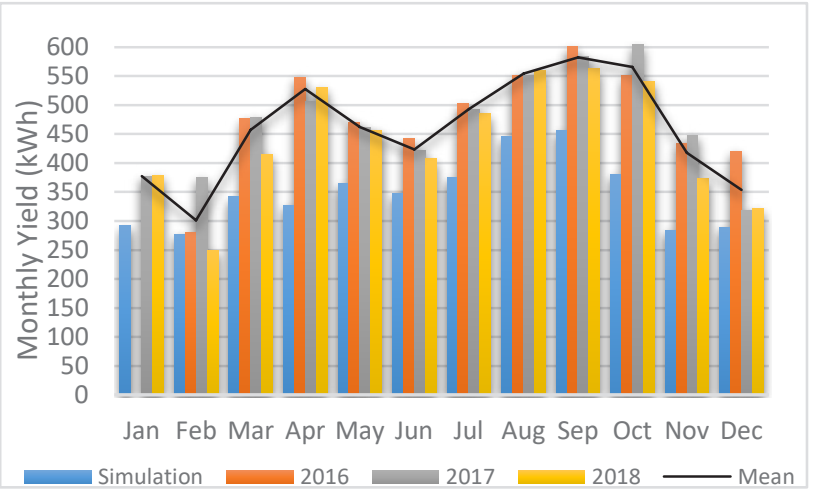

Fig. 3. Monthly yield comparison.

It can be clearly seen from this graph that real (experimental) electricity generation values were higher for almost all of the months and years. The yearly yields were $5278.02 \mathrm{kWh}, 5616.24 \mathrm{kWh}$ and 5283.4 for 2016, 2017 and 2018, respectively. The low electricity yield for 2016 is due to the installation date (Feb 8,2016) while the low yield of 2018 might be explained with weather conditions. When we compare the months among each other we see that the maximum yield was achieved during fall months such as September and October, while the minimum yield was in February.

In the next part of the study, monthly yields have been divided into 6 parts in Fig. 4 to see the distributions of each month. When we look at this figure we can see that during summer months the yield is medium, while the maximum yield was achieved during spring and fall months. This is pretty unconventional compared to a standard rooftop or stand-alone PV system and the reason for that is mainly the tilt angle being $90^{\circ}$ for a façade. Because, when the tilt angle is $90^{\circ}$, the angle of incidence for a façade-type BIPV system becomes less in summer months and high in winter months and for this reason the peak does not happen in summer months although daily sunshine duration is higher.

$$
P R=\frac{\frac{\tau \sum P_{A C}}{P_{S T C}}}{\frac{\tau \sum I}{I_{S T C}}}
$$




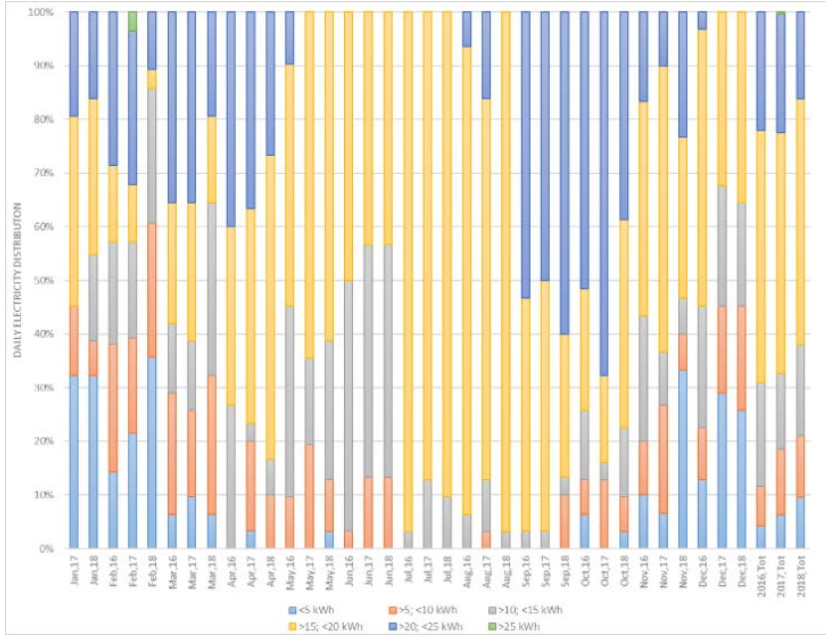

Fig. 4. Monthly average of daily electricity generation distribution.

To further investigate the unconventional profile of the BIPV system, one sunny day of each month has been selected for 2018 to be able to understand power distribution during the day. In this regard, peak powers, the time we reach to the peak power, sunhours and average air temperatures are illustrated in Fig. 5. It can be observed from this figure that although we have more sunny hours during summer, the air temperature is also higher which leads to a decrease in the efficiency of the system and the peak powers occurred during fall and winter months. In fact, the minimum peak power is found to be in June, which is mainly related to the low incidence angle. The peak times were also before midday, changing between 10 to 11 A.M.

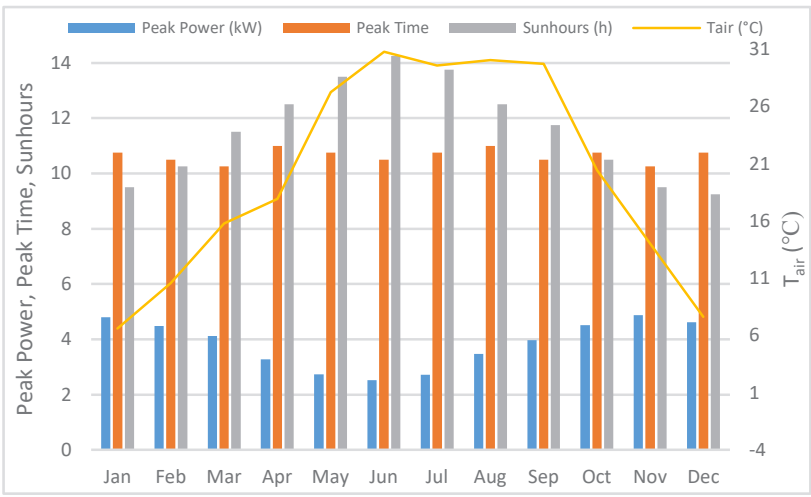

Fig. 5. Peak power, peak time, sunhours and air temperatures during the year.

Next, the power distributions during the day for each season are calculated using the average values of selected days and is shown in Fig. 6. One will notice from this figure that during spring and summer we have less power generation during the day but for longer periods, while the situation is the opposite for winter and fall.

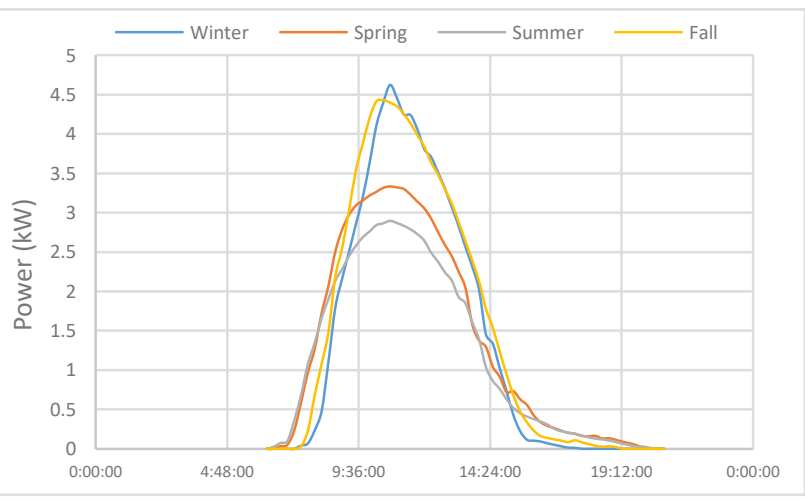

Fig. 6. Seasonal average power distributions during the day.

In the next part of the study, the energy efficiency of the system is estimated for each month of the year and compared with the results obtained from the simulation. This comparison is given in Fig. 7, where we can see that experimental efficiencies are higher for each month of the year. The higher experimental efficiencies are mainly related to the lower experimental surface temperatures. The difference between the experimental and simulated surface temperatures found to be around $\% 16$ for the whole year.

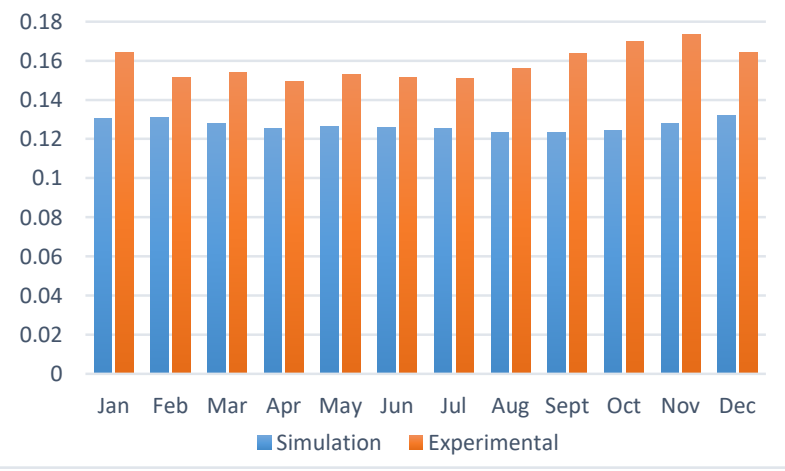

Fig. 7. Energy efficiency comparison.

Lastly, energetic and exergetic efficiencies and also PR values of the BIPV system are calculated based on the cell area and total area. The efficiency results are illustrated along with the irradiation and module surface temperature values in Fig. 8, while PR results are given in Fig. 9.

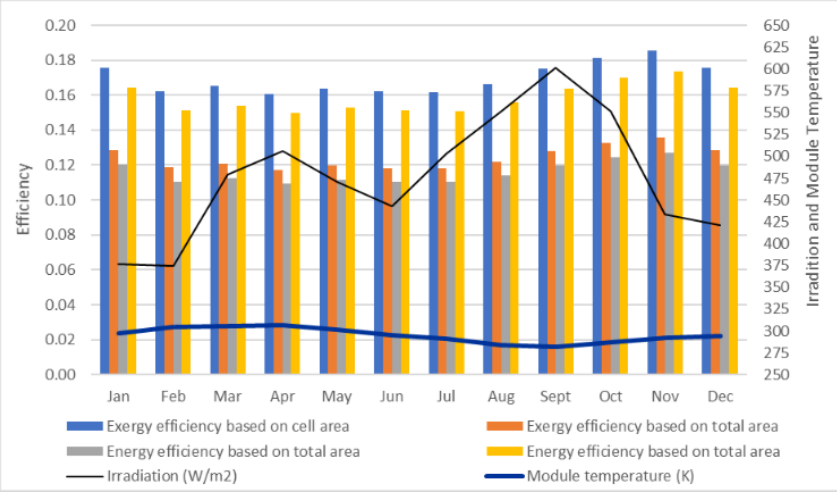

Fig. 8. Efficiency comparison. 


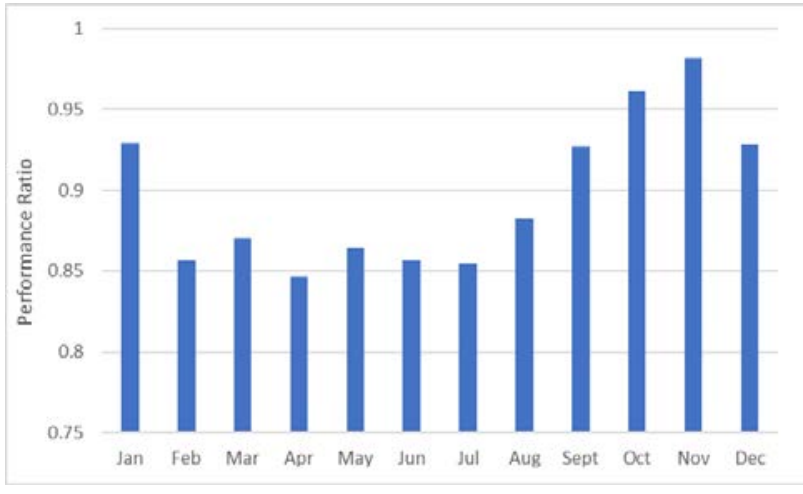

Fig. 9. Performance ratio values of each month.

When we look at Fig. 8, we see that efficiencies based on the cell area are always higher as expected and this is also the case for exergetic efficiencies being always higher than energy efficiencies. The difference between efficiencies based on total area and cell area were found to be around $4 \%$, while the difference between exergy and energy efficiencies is approximately $1.5 \%$. On the other hand we can also observe that efficiencies in hot months is lower than those of cold months.

Lastly, when we look at the obtained PR values, we see a similar trend like efficiency and the values ranged between 0.846 and 0.982 . The highest PR is obtained in November while the lowest was in April.

\section{Conclusions}

In this study, a $7.44 \mathrm{~kW}_{\mathrm{p}}$ BIPV system installed at Yasar University, İzmir, Turkey is experimentally evaluated for a three-year period, using some performance indicators such as energy efficiency, exergy efficiency and PR. The main conclusion that can be drawn from this study can be listed as follows:

(i) BIPV is a promising technology in achieving the targets of EU towards nearly zero energy buildings.

(ii) The experimental monthly electricity generation values were almost always higher than the values obtained from simulation.

(iii) The maximum monthly yield was on October, 2017 with $604 \mathrm{kWh}$, while the minimum yield has occurred on Feb, 2018 (250 kWh).

(iv) Daily electricity yields were between 10 to 20 $\mathrm{kWh}$ for summer days, while the maximum yields were during season changes.

(v) Experimental efficiency values were found to be around 3\% higher than those of simulation's. Lower experimental surface temperatures can be addressed for this situation.

(vi) Energy efficiencies based on total area ranged between $11.1 \%$ to $12.7 \%$, while exergy efficiencies based on total area were in the range of $11.8-13.6 \%$. (vii) Performance ratios followed a similar trend to efficiencies having a maximum of 0.982 in November and a minimum of 0.846 in April.

(viii) For further work, weather corrected performance ratios can be calculated to reduce the fluctuation. Also, one of the methods covered in IEC 60891 can be applied to the system to convert the measured values to standart test conditons and understand the degrading rate of the system.

\section{Acknowledgements}

The presented work was developed within the framework of project "REELCOOP - Research Cooperation in Renewable Energy Technologies for Electricity Generation", co-funded by the European Commission (FP7 ENERGY.2013.2.9.1, Grant agreement no: 608466).

\section{References}

1. G.N. Tiwari, H. Saini, A. Tiwari, A. Deo, N. Gupta, and P.S. Saini, Periodic Theory of Building Integrated Photovoltaic Thermal (BIPVT) System, Sol. En., 125, 373-380 (2016).

2. EU Buildings, https://ec.europa.eu/energy/en/topics/energyefficiency/buildings (Access Date: 19 January 2017).

3. M. Tabakovic, H. Fechner, W.V. Sark, A. Louwen, G. Georghiou, G. Makrides, E. Loucaidou, M. Ioannidou, I. Weiss, S. Arancon, Status and outlook for building integrated photovoltaics (BIPV) in relation to educational needs in the BIPV sector, Energy Procedia, 111, 993-999 (2017).

4. E. Biyik, M. Araz, A. Hepbasli, M. Shahrestani, R. Yao, L. Shao, E. Essah, A.C. Oliveira, T. del Caño, E. Rico, J.L. Lechón, L. Andrade, A. Mendes, Y. Baver Atl1, A key review of building integrated photovoltaic (BIPV) systems, Eng. Sci. and Tech., an Int. J., 20, 833-858 (2017).

5. REELCOOP, Research Cooperation in Renewable Energy Technologies for Electricity Generation report. Seventh Framework Programme of the European Union (2015).

6. R. Rawat, R. Lamba, S.C. Kaushik, Thermodynamic study of solar photovoltaic energy conversion: An overview, Ren. and Sust. En. Rev., 71, 630-638 (2017).

7. R. Petela, Exergy of undiluted thermal radiation, Sol. En., 74, 469-488 (2003).

8. S.A. Klein et al., TRNSYS 17: A transient system simulation program. 2009, Wisconsin: Solar Energy Laboratory, University of Wisconsin. 